\title{
Elimination diets in the management of eosinophilic esophagitis
}

This article was published in the following Dove Press journal:

Journal of Asthma and Allergy

24 May 2014

Number of times this article has been viewed

\section{Joshua B Wechsler \\ Sally Schwartz \\ Katie Amsden \\ Amir F Kagalwalla}

Department of Pediatrics, Division of Gastroenterology, Hepatology and Nutrition, Ann \& Robert H. Lurie Children's Hospital of Chicago, IL, USA
Correspondence: Amir F Kagalwalla Department of Pediatrics, Division of Gastroenterology, Hepatology and Nutrition, Ann \& Robert H. Lurie Children's Hospital of Chicago, $225 \mathrm{E}$. Chicago Ave, Chicago, IL 606I I, USA

Tel + I 3122274200

Fax + I 3122279645

Email akagalwalla@luriechildrens.org
Abstract: Eosinophilic esophagitis, an increasingly recognized chronic inflammatory disorder isolated to the esophagus, is triggered by an abnormal allergic response to dietary antigens. Current treatment includes swallowed topical steroids and dietary modification, which aim to resolve symptoms and prevent long-term complications such as formation of strictures. The dietary approach has become more widely accepted because long-term steroid therapy is associated with potential risks. Dietary treatment includes elemental and elimination diets. An exclusive elemental diet, which requires replacement of all intact protein with amino acidbased formula, offers the best response of all available therapies, with remission in up to $96 \%$ of subjects proving it to be superior to all other available therapies including topical steroids. However, compliance with this approach is challenging because of poor taste and monotony. The high cost of formula and the associated psychosocial problems are additional drawbacks of this approach. Empiric and allergy test-directed elimination diets have gained popularity given that elimination of a limited number of foods is much easier and as such is more readily acceptable. There is a growing body of literature supporting this type of therapy in both children and adults. This paper reviews the evidence for all types of dietary therapy in eosinophilic esophagitis.

Keywords: eosinophilic esophagitis, dietary therapy, empiric elimination, elemental, allergy test-directed

\section{Introduction}

Eosinophilic esophagitis (EoE) is a rapidly emerging allergic disease driven by a dysfunctional immune response to food antigens. ${ }^{1}$ It is characterized by recurrent or chronic symptoms of esophageal dysfunction and dense eosinophil-predominant inflammation isolated to the esophagus that is nonresponsive to high-dose acid suppression. ${ }^{1}$ The disease has increasing prevalence, with recent estimates at 6 per 10,000 individuals in the USA and Europe, ${ }^{2}$ and there is significant morbidity due to frequent symptoms and long-term complications. ${ }^{3,4}$ Symptoms vary by age, and include feeding aversion, food intolerance, and poor growth in infants, vomiting in young children, abdominal pain in school-aged children, and dysphagia and food impaction in adolescents and adults. ${ }^{5}$ The major complication of unbridled chronic eosinophilic inflammation is tissue remodeling, characterized by fibrostenotic changes, which manifest as esophageal narrowing, dysmotility, and stricture formation. These complications often require repeated dilatation, which has significant risk for perforation and morbidity. ${ }^{6,7}$ Although the natural history of the disease is not fully elucidated, EoE is a chronic disorder, and delay in diagnosis increases the risk for stricture formation in a time-dependent manner, with doubling of the risk of fibrostenosis for every 10 years of disease ${ }^{8-10}$ It can 
thus be inferred from these data that diagnosed but untreated disease also incurs a risk of fibrostenotic disease, and as such, the goals of treatment should include induction and maintenance of mucosal healing (histologic remission) and not be limited only to resolution of clinical symptoms.

The primary goals of therapy are resolution of clinical symptoms, maintenance of histologic remission, and prevention of long-term complications. Although the impact of successful therapy on the natural history of EoE has not been elucidated, effective treatment has been shown to reverse subepithelial fibrosis and thus can potentially prevent complications such as remodeling and strictures. ${ }^{11,12}$ Two additional goals in personalizing therapy include prevention of treatment-related adverse reactions and maintenance of quality of life. Dietary modification and swallowed steroids are the two main therapeutic approaches in EoE. Swallowed steroids are the most commonly prescribed therapy to treat EoE, and although the response is excellent, the disease recurs once the steroid is withdrawn. Long-term steroid use raises concerns for adverse reactions, such as opportunistic fungal and viral esophagitis. There are also concerns about the potential impact of longer-term steroid administration on bone mineral density and linear growth. ${ }^{13-15}$ For all of these reasons, dietary therapy is an attractive treatment option for many patients, and this is especially true for young children who will have the disease for a longer duration. The available dietary approaches include an exclusive elemental diet with an amino acid-based complete liquid formulation, an allergy test-directed elimination diet, and an empiric elimination diet that excludes common disease-exacerbating (trigger) foods. The specific treatment selected should be tailored to the nutritional and psychosocial needs of the patient while considering the risks and benefits. Unfortunately, there are no prospective studies directly comparing the efficacy of the different dietary approaches. A recent meta-analysis of all published retrospective and prospective studies showed that the overall effectiveness of all available dietary treatments with regard to inducing histologic remission in EoE was $66.3 \%$ (95\% confidence interval 56.9-75.0) and that there were no significant differences in response between pediatric and adult patients. ${ }^{16}$ Direct comparisons between studies are difficult since different histologic remission endpoint criteria are used. Furthermore, it is difficult to study the clinical response to therapy, given the wide range of symptoms and accommodative eating behaviors. This article aims to review the available literature regarding dietary therapy for EoE, focusing on the efficacy of each option, along with its advantages and disadvantages.

\section{Elemental diets}

An elemental diet, a liquid formulation, is a complete source of nutrition, replete with carbohydrates, fats, minerals, and micronutrients, with crystalline amino acids providing the protein source. Thus, removal of intact protein eliminates all potential food antigen triggers that could stimulate an immune response and forms the basis for this treatment.

\section{Elemental diet works rapidly and provides evidence that EoE is food antigen-mediated}

In a landmark and seminal article in 1995, Kelly and Sampson demonstrated resolution of clinical symptoms and eosinophilpredominant proton pump inhibitor-refractory esophagitis in ten children treated exclusively with an amino acid-based elemental formula for 6 weeks. ${ }^{17}$ Symptoms improved or resolved completely in all ten children. On follow-up endoscopy, peak eosinophil counts decreased significantly from a median of 41 (range 15-100) to 0.5 (range 0-22) and the reactive epithelial changes of the esophageal mucosa improved significantly after introduction of the elemental formula. During reintroduction of food, there was recurrence of symptoms and inflammation, allowing identification of patient-specific trigger foods, which included cow's milk, wheat, egg, soy, and peanuts. These findings, which form the foundation for all dietary therapy, provided direct evidence that food antigens are the primary mediator of the pathogenesis of EoE.

In 2003, Markowitz et al in Philadelphia, PA, USA, assessed the response to an exclusive elemental diet after one month in a cohort of 51 children with symptoms of chronic gastroesophageal reflux disease. These subjects had been unresponsive to 3 months of proton pump inhibitor therapy, and demonstrated eosinophil-predominant inflammation isolated to the esophagus. ${ }^{18}$ Overall improvement in symptoms such as vomiting, abdominal pain, and dysphagia was noted in $96 \%$ of patients with an average time to clinical improvement of 8.5 days. Median esophageal eosinophil count decreased from $34 \pm 10$ eosinophils per high-powered field (eos/hpf) to $1 \pm 1$ following treatment. This study, in addition to validating the initial findings of Kelly et al, provided important insight into the duration of therapy necessary for induction of remission with elemental diet. These reports form the basis of the current time frame from start of therapy to our initial endoscopic assessment of a therapeutic response, because rapid food reintroduction is an important goal. 


\section{Elemental diets are effective in children}

Since these initial reports, several retrospective studies have assessed the overall remission rate of elemental diet in children, and the results of these studies are identical. In 2005, Liacouras et al assessed its efficacy in 172 children (112 males) with a mean age of $8.1 \pm 4.3$ years. ${ }^{19}$ Clinical improvement and resolution of esophageal eosinophilia (from $40 \pm 10$ eos/hpf pretreatment to $1 \pm 1$ eos/hpf post-treatment) was demonstrated in 160 of $164(97 \%)$. Only 35 (20\%) were able to ingest the formula orally, and the remaining $137(80 \%)$ required the formula to be delivered via nasogastric tube. Our own experience is similar, in that patients on elemental formula are unable to ingest the liquid formulation by mouth and quite frequently require administration via a nasogastric or gastrostomy tube. ${ }^{20}$

In our own experience published in 2006, all 25 children treated with elemental diet had complete clinical improvement, and histologic remission was demonstrated in 22/25 $(88 \%) .{ }^{20}$ Our more recent experience, published in 2012, demonstrated histologic remission in 10/12 (83\%) children of mean age $4.6 \pm 6.0$ years treated with an exclusive elemental formula. ${ }^{21}$ Henderson et al reported remission in 47 of $49(96 \%)$ children treated with elemental diet. ${ }^{22}$ Complete remission (0-1 eos/hpf) was noted in 29/49 patients, partial remission ( $2-5$ eos/hpf) in 13/49 patients, and partial resolution $(<15 \mathrm{eos} / \mathrm{hpf})$ in $5 / 49$ patients. Taken together, these studies demonstrate excellent efficacy for the elemental diet in children with EoE, with a success rate ranging from $83 \%$ to $97 \%$. The likely reasons for treatment failure or partial response include lack of full compliance, contamination, and the possibility of additional pathogenic triggers beyond dietary antigens, which may include aeroallergens. $^{23,24}$

\section{Elemental diets are effective in adults}

In adults, the Peterson group in Salt Lake City, UT, USA, assessed the response to 2-4 weeks of elemental diet in adults ( $56 \%$ male) with a mean age of $34 \pm 12$ years. ${ }^{25} \mathrm{After}$ therapy, tissue eosinophilia decreased from $54 \pm 32$ eos/hpf before treatment to $10 \pm 12 \mathrm{eos} / \mathrm{hpf}$ at completion of treatment. Of the 18 patients who completed the trial, 13 (72\%) demonstrated remission and an additional 4 (22\%) demonstrated a decrease in eosinophilic inflammation. One adult failed to demonstrate any improvement in inflammation. The response rate histologically appears to be similar in children; however, many adults experienced significant weight loss, poor symptom improvement, and had limited compliance (62\%). This study highlights the role of dietary antigens in adults as an important driver of disease. It also demonstrates the incredible difficulty of compliance with elemental diet, and a key difference between children, who have inflammatory disease that drives symptoms, and adults, who have fibrostenotic disease that does not entirely improve after removal of the inflammatory insult.

To date, a total of 13 studies (12 in children and one in adults) including a total of 429 EoE patients (411 children and 18 adults) have demonstrated an overall efficacy of elemental diet in inducing histologic remission of $90.8 \%$ (95\% confidence interval 84.7-95.5). ${ }^{16}$

\section{Difficulties of elemental diets}

Although there are no randomized controlled trials assessing the efficacy of elemental diets, observational studies (summarized in Table 1) have provided compelling evidence that it is extremely effective in EoE. Comparison studies from retrospective cohorts support superiority of elemental diets compared with empiric or allergy test-directed elimination

Table I Summary of studies of elemental formula

\begin{tabular}{|c|c|c|c|c|c|c|c|}
\hline Reference & $\mathbf{n}$ & Population & Design & Mean age, years & $\begin{array}{l}\text { Clinical } \\
\text { response }\end{array}$ & $\begin{array}{l}\text { Histologic } \\
\text { response }\end{array}$ & $\begin{array}{l}\text { Residual } \\
\text { eosinophil count }\end{array}$ \\
\hline Kelly et al ${ }^{17}$ & 10 & Children & Prospective & $\begin{array}{l}4.8 \text { ( } 8 \text { months to } \\
\text { I } 2.5 \text { years) }\end{array}$ & $10 / 10(100 \%)$ & $\begin{array}{l}<20 \text { eos/hpf: } \\
9 / 10(90 \%)\end{array}$ & $\begin{array}{l}4 \mathrm{I} \rightarrow 0.5 \\
(P=0.005)\end{array}$ \\
\hline Markowitz et al ${ }^{18}$ & 51 & Children & Retrospective & $8.3 \pm 3.1$ & 49/5I (96\%) & $\begin{array}{l}<20 \text { eos/hpf: } \\
49 / 5 \text { I }(96 \%)\end{array}$ & $\begin{array}{l}33.7 \rightarrow 1.0 \\
(P<0.0 \mathrm{I})\end{array}$ \\
\hline Liacouras et al ${ }^{19}$ & 172 & Children & Retrospective & $8.1 \pm 4.3$ & I60/I 64 (98\%) & $\begin{array}{l}<20 \text { eos/hpf: } \\
\text { I60/I } 64 \text { (98\%) }\end{array}$ & $\begin{array}{l}38.7 \rightarrow \mathrm{I} . \mathrm{I} \\
(P<0.00 \mathrm{I})\end{array}$ \\
\hline Kagalwalla et al ${ }^{20}$ & 25 & Children & Retrospective & 6.4 & $25 / 25(100 \%)$ & $\begin{array}{l}\leq 10 \text { eos/hpf: } \\
22 / 25(88 \%)\end{array}$ & $\begin{array}{l}58.8 \rightarrow 3.7 \\
(P<0.00 I)\end{array}$ \\
\hline Peterson et $\mathrm{al}^{25}$ & 18 & Adults & Prospective & $34 \pm 12$ & $\begin{array}{l}\text { No clinical } \\
\text { improvement }\end{array}$ & $\begin{array}{l}\leq 10 \text { eos/hpf: } \\
13 / 18(72 \%)\end{array}$ & $\begin{array}{l}54 \rightarrow 10 \\
(P=0.0006)\end{array}$ \\
\hline Henderson et $\mathrm{al}^{22}$ & 49 & Children & Retrospective & 5.6 & Not available & $\begin{array}{l}<15 \text { eos/hpf: } \\
47 / 49(96 \%)\end{array}$ & $\begin{array}{l}5 \mathrm{I} .0 \rightarrow 1.0 \\
(P<0.000 \mathrm{I})\end{array}$ \\
\hline
\end{tabular}

Abbreviation: eos/hpf, eosinophils per high-powered field. 
diets, including that mucosal healing can be achieved with even greater efficacy than with pharmacologic therapy. In addition, since elemental formula provides complete nutrition, nutritional deficiencies do not occur, as is likely with other types of dietary approaches if careful attention is not paid to replacing excluded nutrients with adequate alternative substitutes. Elemental diets are often well accepted by EoE patients presenting with significant malnutrition; ${ }^{26}$ however, despite the near-perfect response rate, these diets are generally reserved for patients who fail elimination diets because this type of therapy has major disadvantages. To start with, elemental diets are expensive, a cost that is not always covered by insurance, and their poor taste makes them relatively unpalatable, despite a growing number of flavor options. Thus, many patients require feeds to be delivered via a nasogastric or gastrostomy tube to allow for sufficient intake of calories necessary to prevent growth failure. ${ }^{18}$ In young children, long-term use of exclusive elemental formula may hinder the development of oromotor function and may lead to feeding aversion and other unintended adverse psychosocial effects that hinder quality of life. In older children and adults, inability to eat solid foods, particularly in social situations, may also affect quality of life. Not surprisingly, while compliance is reasonable in young children, it is problematic in older children and nearly impossible for many adults. ${ }^{19,25}$ Finally, the number of endoscopies required for successful food reintroduction is significantly higher and the duration required to complete reintroduction is longer than for other types of dietary elimination. ${ }^{22}$ In our practice, the period of exclusive elemental formula is limited to 4 weeks prior to therapeutic assessment by endoscopy, and reintroduction of solid foods is based on their relative propensity to promote active disease. As noted in Table 2, foods are divided into four groups, and single foods are introduced every 5-7 days from within a group followed by an endoscopy one month after three to four foods are clinically tolerated. For foods in groups C and D, food reintroduction is more conservative, and typically at least 9-12 months are required to obtain a decent variety in the diet. To enhance compliance, single foods with low potential for disease exacerbation, such as apple or grape, are offered along with "freebie" foods that are protein-free to enhance variety (Table 3 ).

\section{Elimination diets}

Elimination diets include allergy test-directed elimination, empiric removal of common trigger foods, or a combination of both. These diets offer patients more food choices and are therefore more palatable with greater compliance, although their success rate is inferior to elemental diet.

\section{Allergy test-directed elimination: the search for a smart and simple approach}

The clinical evidence of allergic sensitization to various foods along with their causal nature fueled a number of studies evaluating the efficacy of allergy testing to guide food elimination. ${ }^{27-29}$ In theory, this could simplify the elimination process by avoiding the unnecessary removal of certain foods. This has proven to be somewhat difficult because the pathogenesis of EoE is complex, involving both immunoglobulin E (IgE)-mediated and cell-mediated allergic mechanisms. ${ }^{30-33}$ While IgE is not directly involved in the trafficking of eosinophils to the esophagus, ${ }^{32-34}$ it may play a role in mediating clinical symptoms. ${ }^{34,35}$ Specific-IgE can be quantified by serum testing (ImmunoCAP ${ }^{\circledR}$, Thermo Fisher

Table 2 Food reintroduction approach in eosinophilic esophagitis

\begin{tabular}{|c|c|c|c|}
\hline \multicolumn{3}{|l|}{$\begin{array}{l}\text { Start } \\
\text { (least allergenic) }\end{array}$} & \multirow{2}{*}{$\begin{array}{l}\text { End } \\
\text { (most allergenic) } \\
\text { D }\end{array}$} \\
\hline $\mathbf{A}$ & B & C & \\
\hline Vegetables & Citrus fruit & Legumes & Fish/Shellfish \\
\hline (nonlegume) & Orange, grapefruit, lemon, lime & Lima beans, chickpeas, & Corn \\
\hline Carrots, squash (all types), sweet & Tropical fruit & white/black/red beans & Peas \\
\hline potato, white potato, string beans, & Banana, kiwi, pineapple, mango, & Grains & Peanut \\
\hline broccoli, lettuce, beets, asparagus, & papaya, guava, avocado & Oat, barley, rye & Wheat \\
\hline cauliflower, Brussels sprouts & Melons & other grains & Beef \\
\hline Fruit & Honeydew, cantaloupe, watermelon & Meat & Soy \\
\hline (noncitrus, nontropical) & Berries & Lamb, chicken, turkey, & Egg \\
\hline $\begin{array}{l}\text { Apple, pear, peaches, plum, apricot, } \\
\text { nectarine, grape, raisins }\end{array}$ & $\begin{array}{l}\text { Strawberry, blueberry, } \\
\text { raspberry, cherry, cranberry }\end{array}$ & pork & Milk \\
\hline Vegetables & Grains & & \\
\hline $\begin{array}{l}\text { Tomatoes, celery, cucumber, } \\
\text { onion, garlic, any other vegetables }\end{array}$ & Rice, millet, quinoa & & \\
\hline
\end{tabular}


Table 3 "Freebie" food list

Below are ingredients allowed on elemental diet, during the food reintroduction phase. Please check the label on every product, every time it is purchased, as ingredients can change. If you have any questions, please contact a registered dietitian from the eosinophilic esophagitis program

- Artificial flavors and/or colors

- Artificial sweeteners

- Ascorbic acid (vitamin C)

- Baking soda

- Baking powder

- Corn syrup

- Corn starch

- Dextrose

- Extracts (eg, vanilla, peppermint)

- High fructose corn syrup

- Maltodextrin

- Malic acid

- Margarine/shortenings made from vegetable oils

- Molasses

- Maple syrup

- Oils: canola, vegetable, safflower (except cold pressed, expellerpressed, or extruded oils)

- Potato starch

- Rice syrup

- Rice starch/dextrin

- Tartaric acid

- Tapioca starch

- Salt

- Sugar (white/brown)

- Vinegar (distilled)

- Xanthan gum

- Water

- Yeast

Candies and drinks should contain only sugar and artificial flavors and colors: limit to I-2 servings/day

- Dum Dum lollipops

- Kool-Aid

- Crystal Light

- Pedialyte ${ }^{\circledR}$ (Abbott Laboratories, Abbott Park, IL, USA) not Pedialyte Advanced Care: contains milk

- Fla-Vor-Ice freezer pops (artificially flavored)

Scientific, Waltham, MA, USA $)^{36}$ for which there are minimal data regarding its utility in guiding elimination diets, and skin prick testing, which assesses the presence and function of food-specific IgE bound to mast cells in the skin. ${ }^{36}$ Skin prick testing remains critical for assessing the potential for anaphylaxis due to loss of tolerance in EoE patients with prolonged food restriction. Non-IgE, cell-mediated allergic reactions can be assessed by atopy patch testing, where fresh or rehydrated foods are applied in specialized chambers to the back for 48-72 hours, followed by assessment of the skin for erythema, induration, and papule formation..$^{36}$ The use of this test has been well documented in contact dermatitis and eczema, and is thought to assess T-lymphocyte reactivity to foods, which likely mediates the recruitment of eosinophils in the esophagus. ${ }^{32}$

\section{Predictive value of allergy test-directed elimination diets}

Spergel et al retrospectively assessed the positive and negative predictive value as well as sensitivity and specificity of skin prick testing and atopy patch testing in a subgroup of 319 patients in which trigger foods could be definitively identified. ${ }^{28}$ For skin prick testing, the precision in detecting true positives for all foods ranged from $26 \%$ to $62 \%$, except for milk (86\%). However, the precision in detecting true negatives was $\geq 86 \%$ for soy, egg, peanuts, beef, corn, chicken, potato, and pork, while wheat (78\%) and milk (29\%) were reduced. The true positive rate (sensitivity) of skin prick testing was low for all foods except peanuts (88\%), and the true negative rate (specificity) was $\geq 86 \%$ for all foods. The findings for atopy patch testing were similar, with a negative predictive value $\geq 86 \%$ for all foods except milk (31\%), and the positive predictive value for all foods ranged from $12 \%$ to $51 \%$, except for milk ( $86 \%$ ). The sensitivity of atopy patch testing was low, except for corn (92\%), and the specificity was $\geq 82 \%$ for all foods. Combining skin prick testing and atopy patch testing increased the negative predictive value to $\geq 93 \%$ for all foods, except for milk (44\%) and wheat (88\%); however, the positive predictive value remained low for all foods, except milk ( $82 \%)$. The sensitivity of combined testing improved with egg, peanuts, corn, chicken, and potato ( $\geq 81 \%$ ), but the specificity decreased $(72 \%-90 \%)$. While aspects of these results are somewhat appealing, they remain difficult to interpret due to the retrospective nature of the study and the inability to reproduce identical results. Notably, a retrospective study from Cincinnati, OH, USA, found a lower negative predictive value for skin prick testing to soy (64\%), egg (56\%), and wheat (67\%). ${ }^{22}$ Taken together, this suggests that while negative tests are somewhat encouraging (except for milk), positive tests often lead to a false positive result.

\section{Efficacy of allergy test- directed elimination diets}

Although many patients demonstrate abnormal allergy tests to food, the efficacy in directing food elimination is a bigger question. The use of this modality was initially described in 2002 by Spergel et al. ${ }^{29}$ Foods identified by a combination of skin prick testing and atopy patch testing were eliminated in 24 pediatric patients. On average, five foods were eliminated, 
leading to histologic remission in 18/24 (75\%). Among these subjects, tissue eosinophilia decreased from $56 \pm 25$ eos/hpf to $8 \pm 8$ eos/hpf, and was accompanied by improvement in symptoms. In 2005, the same group retrospectively assessed the efficacy of this approach in 146 children of mean age $6.5 \pm 4.5$ years. ${ }^{27}$ Patients were tested for a total of 23 foods in five food groups that included meats (chicken, turkey, beef, and pork), vegetables (peas, string beans, squash, sweet potatoes, potatoes, and carrots), fruit (apples, pears, and peaches), and grains (wheat, rice, rye, oats, barley, and corn), along with cow's milk, soy, eggs, and peanuts. The foods most frequently identified in patients who underwent a combination of atopy patch testing and skin prick testing were milk, soy, wheat, chicken and beef. Forty patients required elemental diet due to a high number of positive allergy tests $(>10)$ or poor compliance with the recommended elimination diet. Thirty-nine of the forty subjects were histologic responders ( $<5$ eos/hpf). Seventy-two patients (49\%) were able to follow the recommended elimination diet and were histologic responders, and 19 patients $(13 \%)$ were partial responders with a reduction in tissue eosinophils from $69 \pm 26 \mathrm{eos} / \mathrm{hpf}$ pre-diet to $12 \pm 3$ postdiet. Notably, both groups showed significant symptomatic improvement. This research group retrospectively reviewed the efficacy of this approach again in 2012 and found a response rate of $53 \%$, which improved to $77 \%$ with the empiric elimination of milk. ${ }^{28}$ From this work, it appears that allergy test-directed elimination alone may be effective for about $50 \%$ of patients; however, this approach is complicated by a large number of false positives, often necessitating transition to elemental diet to maintain adequate nutrition.
Other groups have assessed this approach, and found significantly reduced efficacy in children and adults. Al-Hussaini et al observed a partial histologic response in $40 \%$ of pediatric patients and Rizo Pascual et al observed a similar response rate of $45 \% .^{37,38}$ Liacouras et al retrospectively observed disease remission in 18/75 (24\%) pediatric patients, ${ }^{19}$ and Henderson et al noted a response rate of $65 \%$ in children with this approach. ${ }^{22}$ Small studies in adults by Simon et al and Gonzalez-Cervera et al found essentially no clinical benefit, and Molina-Infante et al found disease remission in only 4/15 (24\%) subjects. ${ }^{39-41}$ The overall efficacy in 626 patients (594 children and 32 adults) treated with an allergy test-directed diet thus far is $45.5 \%$ (95\% confidence interval 35.4-55.7). ${ }^{16}$ Thus, the cumulative data summarized in Table 4 and the results of the meta-analysis demonstrate that the overall response rate with an allergy-tested diet is less than $50 \%$. This has led Arias et al to question whether allergy test-directed food elimination should even be recommended for EoE patients. ${ }^{16}$

\section{Difficulty with allergy test-directed elimination}

Allergy test-directed dietary elimination has the advantage of allowing the fewest foods to be removed ${ }^{28}$ however, it has a relatively high false negative rate. This is underscored by its overall poor efficacy observed in studies in children and adults. $^{22,28,31,37,40,42}$ The high false negative rate may be in part due to poor standardization or difficulty with reproducibility, particularly for atopy patch testing. ${ }^{43,44}$ Specific food preparation is a likely factor and fresh foods elicit more positive

Table 4 Summary of allergy test-directed elimination studies

\begin{tabular}{|c|c|c|c|c|c|c|c|c|}
\hline Reference & $\mathbf{n}$ & Population & Design & $\begin{array}{l}\text { Mean age, } \\
\text { years }\end{array}$ & $\begin{array}{l}\text { Type of } \\
\text { allergy testing }\end{array}$ & $\begin{array}{l}\text { Clinical } \\
\text { response }\end{array}$ & $\begin{array}{l}\text { Histologic } \\
\text { response }\end{array}$ & $\begin{array}{l}\text { Residual } \\
\text { eosinophil count }\end{array}$ \\
\hline $\begin{array}{l}\text { Teitelbaum } \\
\text { et } \mathrm{al}^{49}\end{array}$ & II & Children & Prospective & $8 \pm 0.9$ & SPT, RAST & No improvement & Not available & Not available \\
\hline $\begin{array}{l}\text { Spergel } \\
\text { et } \mathrm{al}^{29}\end{array}$ & 26 & Children & Prospective & $6.93 \pm 3.5$ & SPT, patch & $24 / 24(100 \%)$ & $\begin{array}{l}<15 \text { eos/hpf: } \\
18 / 24(75 \%)\end{array}$ & $55.8 \rightarrow 8.4$ \\
\hline $\begin{array}{l}\text { Spergel } \\
\text { et } \mathrm{al}^{27}\end{array}$ & 146 & Children & Retrospective & $6.5 \pm 4.5$ & SPT, APT & | 3 |/ 46 (89\%) & $\begin{array}{l}<5 \text { eos/hpf: } \\
72 / \mid 46(49 \%)\end{array}$ & $48.4 \rightarrow I . I$ \\
\hline $\begin{array}{l}\text { Simon } \\
\text { et } \mathrm{al}^{41}\end{array}$ & 6 & Adults & Prospective & $25.83 \pm 9.0$ & SPT & $1 / 6(17 \%)$ & $0 / I(0 \%)$ & Not available \\
\hline $\begin{array}{l}\text { Rizo Pascual } \\
\text { et } \mathrm{al}^{38}\end{array}$ & II & Children & Prospective & 9 & SPT, APT & $5 / I I(45 \%)$ & $\begin{array}{l}<10 \text { eos/hpf: } \\
5 / 11 \text { ( } 45 \%)\end{array}$ & Not available \\
\hline $\begin{array}{l}\text { Molina-Infante } \\
\text { et } \mathrm{al}^{39}\end{array}$ & 15 & Adults & Prospective & $\begin{array}{l}34 \\
(18-62)\end{array}$ & SPT, PPT, APT & $5 / 15$ (33\%) & $\begin{array}{l}\leq 15 \text { eos/hpf: } \\
5 / 15(33 \%)\end{array}$ & $\begin{array}{l}68 \rightarrow 39 \\
(P=0.53)\end{array}$ \\
\hline $\begin{array}{l}\text { Henderson } \\
\text { et } \mathrm{al}^{22}\end{array}$ & 23 & Children & Retrospective & 5.2 & SPT, APT & Not available & $\begin{array}{l}<15 \text { eos/hpf: } \\
15 / 23(65 \%)\end{array}$ & $\begin{array}{l}38.0 \rightarrow 7.0 \\
(P=0.003)\end{array}$ \\
\hline $\begin{array}{l}\text { Spergel } \\
\text { et } \mathrm{al}^{28}\end{array}$ & 319 & Children & Retrospective & $\begin{array}{l}\text { Not } \\
\text { available }\end{array}$ & SPT, APT & Not available & $\begin{array}{l}\text { <15 eos/hpf: } \\
(53 \%)\end{array}$ & Not available \\
\hline
\end{tabular}

Abbreviations: SPT, skin prick testing; RAST, radioallergosorbent test; APT, atopy patch testing; PPT, prick-prick test; eos/hpf, eosinophils per high-powered field. 
tests than commercial extracts. ${ }^{39}$ Allergy testing also has a high false positive rate, and a comparative study of different dietary methods reported a longer period for food reintroduction and more endoscopies compared with an empiric elimination diet. ${ }^{22}$ The complex mechanisms that drive EoE, both cell-mediated and IgE-mediated, are likely reasons for the difficulties experienced with allergy test-directed elimination. Additional prospective studies are needed to evaluate its role in managing patients with EoE.

\section{Empiric elimination diet: finding the middle ground}

Unlike the directed elimination diet, the empiric or nondirected elimination diet excludes a fixed number of food allergens, including cow's milk, wheat, egg, soy, peanuts/ tree nuts, and seafood from the diet. It is based on the premise that these six foods are most commonly associated with food allergies in children and are the most commonly reported to cause esophageal mucosal injury in children with EoE. 17,29,45,46 This novel therapeutic approach was first pioneered at our institution, ${ }^{20}$ and has demonstrated high efficacy in inducing clinical and histologic remission in a majority of children and adults with EoE, as summarized in Table 5.

\section{Efficacy of empiric elimination in children}

We reported a cohort of 35 children treated with the sixfood elimination diet (SFED), excluding milk, wheat, egg, soy, peanuts/tree nuts, and seafood for 6 weeks. ${ }^{20}$ Twentysix $(74 \%)$ children experienced significant clinical and histologic improvement ( $\leq 10 \mathrm{eos} / \mathrm{hpf}$ ), and within this group, $7 / 26(27 \%)$ achieved complete mucosal healing ( $\leq 1$ eos/hpf). In a subsequent follow-up study, we demonstrated that milk (74\%), wheat (26\%), egg (17\%), and soy (10\%) were the most common food triggers inducing disease. ${ }^{45} \mathrm{~A}$ single offending food antigen was identified in $72 \%$, and the remaining had either two or three food antigen triggers. Only one child reacted to peanuts and none of the subjects challenged with seafood showed clinical or histologic reactivity.

The efficacy of SFED has since been corroborated by several other retrospective studies in children. Henderson et al demonstrated an even higher response rate, with remission in $81 \%(21 / 26)$ following SFED. ${ }^{22}$ The food reintroduction process took less than a year to complete and subjects required a total of six endoscopies. Thus, based on the findings of this study, children treated with SFED required fewer endoscopies, and the reintroduction period was shorter than for an allergy test-directed elimination or elemental diet, and this should be an important consideration for patients when considering elimination diet therapy. In a second comparative study, Spergel et al reported a hypothetical response rate of $53 \%$ to SFED, which improved to $77 \%$ with removal of meats (chicken, beef, pork, and turkey). This study was based on a retrospective analysis of food triggers discovered in EoE patients who had received allergy test-directed elimination and is thus prone to selection bias. Furthermore, this approach would potentially obscure partial responses (6-14 eos/hpf), which are clinically relevant. ${ }^{28}$

After milk was shown to be the most common trigger food in EoE, a hypothesis-generating retrospective study published in 2012 from our institution reviewed the efficacy of empirically eliminating only cow's milk from the diet of children. ${ }^{21}$ Complete or partial remission $(<15$ eos/hpf) was achieved in $11 / 17(65 \%)$ children of mean age of $5.5 \pm 3.2$ years. Symptom improvement or resolution was reported in all responders. Children who responded to this therapy were younger and tended to have lower pretreatment eosinophil counts; however, the small size of this study and its retrospective nature precludes any significant conclusions. Identifying

Table 5 Summary of empiric elimination studies

\begin{tabular}{|c|c|c|c|c|c|c|c|c|}
\hline Reference & $\mathbf{n}$ & Population & Design & $\begin{array}{l}\text { Mean age, } \\
\text { years }\end{array}$ & Diet & $\begin{array}{l}\text { Clinical } \\
\text { response }\end{array}$ & $\begin{array}{l}\text { Histologic } \\
\text { response }\end{array}$ & $\begin{array}{l}\text { Residual } \\
\text { eosinophil count }\end{array}$ \\
\hline $\begin{array}{l}\text { Kagalwalla } \\
\text { et } \mathrm{al}^{20}\end{array}$ & 35 & Children & Retrospective & 6.2 & SFED & $34 / 35$ (97\%) & $\begin{array}{l}\leq 10 \text { eos/hpf: } \\
26 / 35(74 \%)\end{array}$ & $\begin{array}{l}80.2 \rightarrow 9.4 \\
(P<0.000 I)\end{array}$ \\
\hline $\begin{array}{l}\text { Gonsalves } \\
\text { et } \mathrm{al}^{47}\end{array}$ & 50 & Adults & Prospective & 40 (19-76) & SFED & $94 \%$ & $\begin{array}{l}\leq 10 \text { eos/hpf: } \\
70 \%\end{array}$ & $\begin{array}{l}44 \rightarrow 13 \\
(P<0.0001)\end{array}$ \\
\hline $\begin{array}{l}\text { Kagalwalla } \\
\text { et } \mathrm{al}^{21}\end{array}$ & 17 & Children & Retrospective & $5.5 \pm 3.2$ & Milk only & $17 / 17$ (100\%) & $\begin{array}{l}<\text { I5 eos/hpf: } \\
\text { I I/I7 (65\%) }\end{array}$ & $\begin{array}{l}76 \rightarrow 2^{*} \\
(P<0.0 \mathrm{I})\end{array}$ \\
\hline $\begin{array}{l}\text { Henderson } \\
\text { et } \mathrm{al}^{22}\end{array}$ & 26 & Children & Retrospective & 6.6 & SFED & Not available & $\begin{array}{l}<15 \text { eos/hpf: } \\
21 / 26(81 \%)\end{array}$ & $\begin{array}{l}76.5 \rightarrow 2.5 \\
(P=0.005)\end{array}$ \\
\hline $\begin{array}{l}\text { Lucendo } \\
\text { et } \mathrm{al}^{48}\end{array}$ & 67 & Adults & Prospective & $33.4 \pm 11.0$ & $\begin{array}{l}\text { SFED + legumes, } \\
\text { rice and corn }\end{array}$ & $\begin{array}{l}\text { Significant } \\
\text { Improvement }\end{array}$ & $\begin{array}{l}<15 \text { eos/hpf: } \\
49 / 67(73 \%)\end{array}$ & $\begin{array}{l}47.9 \rightarrow 3.5^{*} \\
(P<0.001)\end{array}$ \\
\hline
\end{tabular}

Note: *Study reported the residual counts of responders only, not all subjects.

Abbreviations: SFED, six-food elimination diet; eos/hpf, eosinophils per high-powered field. 
the particular population group that responds to elimination of cow's milk only would be helpful to limit unnecessary food elimination and endoscopies.

\section{Efficacy of empiric elimination in adults}

Similar results have been observed with empiric elimination in adults with EoE. Gonsalves et al in Chicago, IL, USA, reported a $70 \%$ remission rate ( $\leq 10 \mathrm{eos} / \mathrm{hpf})$ in 50 patients, and a reduction in symptom scores in $94 \%$ of patients. ${ }^{47}$ Milk and wheat were the most frequent disease-exacerbating foods, and skin prick testing was accurate in only $13 \%$ of patients. Using a regionally-adjusted empiric elimination diet, which included classic SFED foods in addition to legumes, rice, and corn, Lucendo et al in Ciudad Real, Spain, reported a response rate of $73 \%$ (49/67), with reduction in mean esophageal eosinophilia from 48 eos/hpf to 4 eos/hpf and significant improvement in clinical symptoms. Additionally, this group demonstrated continuing long-term remission with exclusion of the incriminating food antigens. ${ }^{48}$ Taken together, the findings of these studies suggest that empiric diet may be more efficacious than allergy test-directed diet, given that it offers significantly more food choices, requires fewer endoscopies, and less time to complete food reintroduction. However, elemental diet remains superior to both empiric and allergy test-directed diet.

A total of 197 patients ( 75 children and 122 adults) with EoE have been treated with empiric elimination diet and the efficacy of this treatment modality in inducing histologic remission was $72.1 \%$ (95\% confidence interval $65.8-78.1) .{ }^{16}$

\section{Nutritional assessment is necessary}

Nutritional assessment is critical to initiating and maintaining compliance with an elimination diet. A detailed history should be obtained, which includes a description of food and supplements being consumed, preparation methods, and eating environment. Pre-existing nutritional deficiencies should be assessed and addressed concurrently as part of the therapeutic regimen. Adults on elimination diets require close monitoring of weight, and children require frequent anthropometric measurements, including weight, height, and body mass index. Biochemical monitoring may include complete blood count, pre-albumin, iron, calcium, and vitamin D levels.

\section{Food substitutions and cross-contamination: critical role of the dietitian}

The role of a dietitian with understanding and expertise in food substitution and potential cross-contamination cannot be understated. It is critical, particularly for growing children, to maintain a nutritionally complete diet. This requires knowledge and understanding of the nutrient deficiencies caused by elimination of a specific food as well as the appropriate substitution for that food. Additionally, an experienced dietitian assesses for and attempts to prevent contamination of excluded foods. Cross-contamination, which occurs at the levels of food manufacturing/processing, preparation, cooking, and serving, transforms an antigen-free food into an antigen-containing food. Comprehensive understanding of food manufacturing can help identify potential contamination with one or more foods such as milk, soy, wheat, or nuts. Cross-contamination during food preparation at home can be avoided by measures such as cleaning surfaces and utensils, as well as strict hand-washing between handling/ cooking different foods. Educating patients and families to reading food labels every time food is purchased is critical to finding processed products allowed in the diet, given that manufacturing or processing frequently changes without clear notice to the consumer.

\section{Conclusion}

EoE is characterized by an abnormal allergic-type immune response to dietary antigens. Removal of disease-exacerbating foods has proven to be successful in treating the disease and elimination diets have thus become the mainstay of therapy in EoE. Diet therapy, whether it's empiric/non-directed or allergy test-directed, is an accepted and efficacious alternative to elemental diet that offers improved compliance, better food choices, less food reintroduction, and fewer endoscopies. Optimal selection of an elimination diet depends on the age of the patient, the presence of comorbid malnutrition, and any dysfunctional feeding behaviors, as well as comfort, quality of life, and acceptance of the diet by the patient/family. In the context of the limitations of allergy testing in identifying food triggers in EoE, as addressed at length, we currently do not recommend allergy testing to guide dietary intervention in children and adults but instead recommend empiric elimination diet. The future availability of a minimally or noninvasive test would alleviate the current difficulties with regard to implementing dietary management. The overall success of implementing dietary therapy is contingent upon a multidisciplinary approach involving nutritional support in addition to tailoring specific treatment to the individualized needs of each patient.

Participation of a registered dietitian ensures a calorically adequate diet for growth, provides education on appropriate food substitutions, prevents contamination with excluded food antigens, and is an ongoing resource for families as they 
learn to adapt to diet modification. Future studies will help to shape the ideal balance between nutritional needs, targeted elimination, and the ability to ultimately avoid steroids or elemental diet.

\section{Disclosure}

The authors report no conflicts of interest in this work.

\section{References}

1. Liacouras CA, Furuta GT, Hirano I, et al. Eosinophilic esophagitis: updated consensus recommendations for children and adults. J Allergy Clin Immunol. 2011;128(1):3-20. e6.

2. Straumann A, Schoepfer AM. Therapeutic concepts in adult and paediatric eosinophilic oesophagitis. Nat Rev Gastroenterol Hepatol. 2012;9(12):697-704.

3. Franciosi JP, Hommel KA, Bendo CB, et al. PedsQL eosinophilic esophagitis module: feasibility, reliability, and validity. $J$ Pediatr Gastroenterol Nutr. 2013;57(1):57-66.

4. Menard-Katcher P, Marks KL, Liacouras CA, Spergel JM, Yang YX, Falk GW. The natural history of eosinophilic oesophagitis in the transition from childhood to adulthood. Aliment Pharmacol Ther. 2013;37(1):114-121.

5. Straumann A, Aceves SS, Blanchard C, et al. Pediatric and adult eosinophilic esophagitis: similarities and differences. Allergy. 2012;67(4):477-490.

6. Allen KJ, Heine RG. Eosinophilic esophagitis: trials and tribulations. J Clin Gastroenterol. 2011;45(7):574-582.

7. Jung KW, Gundersen N, Kopacova J, et al. Occurrence of and risk factors for complications after endoscopic dilation in eosinophilic esophagitis. Gastrointest Endosc. 2011;73(1):15-21.

8. Straumann A. The natural history and complications of eosinophilic esophagitis. Thorac Surg Clin. 2011;21(4):575-587.

9. Schoepfer AM, Safroneeva E, Bussmann C, et al. Delay in diagnosis of eosinophilic esophagitis increases risk for stricture formation in a time-dependent manner. Gastroenterology. 2013;145(6):1230-1236. e1-2.

10. Dellon ES, Kim HP, Sperry SL, Rybnicek DA, Woosley JT, Shaheen NJ. A phenotypic analysis shows that eosinophilic esophagitis is a progressive fibrostenotic disease. Gastrointest Endosc. 2014;79(4):577-585. e4.

11. Kagalwalla AF, Akhtar N, Woodruff SA, et al. Eosinophilic esophagitis: epithelial mesenchymal transition contributes to esophageal remodeling and reverses with treatment. J Allergy Clin Immunol. 2012;129(5): 1387-1396. e7.

12. Lieberman JA, Morotti RA, Konstantinou GN, Yershov O, Chehade M. Dietary therapy can reverse esophageal subepithelia fibrosis in patients with eosinophilic esophagitis: a historical cohort. Allergy. 2012;67(10):1299-1307.

13. Schaefer ET, Fitzgerald JF, Molleston JP, et al. Comparison of oral prednisone and topical fluticasone in the treatment of eosinophilic esophagitis: a randomized trial in children. Clin Gastroenterol Hepatol. 2008;6(2):165-173.

14. Pedersen S. Clinical safety of inhaled corticosteroids for asthma in children: an update of long-term trials. Drug Saf. 2006;29(7):599-612.

15. Turpeinen M, Pelkonen AS, Nikander K, et al. Bone mineral density in children treated with daily or periodical inhaled budesonide: the Helsinki Early Intervention Childhood Asthma study. Pediatr Res. 2010;68(2):169-173.

16. Arias A, Gonzalez-Cervera J, Tenias JM, Lucendo AJ. Efficacy of dietary interventions in inducing histologic remission in patients with eosinophilic esophagitis: a systematic review and meta-analysis. Gastroenterology. February 14, 2014. [Epub ahead of print.]

17. Kelly KJ, Lazenby AJ, Rowe PC, Yardley JH, Perman JA, Sampson HA Eosinophilic esophagitis attributed to gastroesophageal reflux: improvement with an amino acid-based formula. Gastroenterology. 1995;109(5):1503-1512.
18. Markowitz JE, Spergel JM, Ruchelli E, Liacouras CA. Elemental diet is an effective treatment for eosinophilic esophagitis in children and adolescents. Am J Gastroenterol. 2003;98(4):777-782.

19. Liacouras CA, Spergel JM, Ruchelli E, et al. Eosinophilic esophagitis: a 10-year experience in 381 children. Clin Gastroenterol Hepatol. 2005;3(12):1198-1206.

20. Kagalwalla AF, Sentongo TA, Ritz S, et al. Effect of six-food elimination diet on clinical and histologic outcomes in eosinophilic esophagitis. Clin Gastroenterol Hepatol. 2006;4(9):1097-1102.

21. Kagalwalla AF, Amsden K, Shah A, et al. Cow's milk elimination: a novel dietary approach to treat eosinophilic esophagitis. J Pediatr Gastroenterol Nutr. 2012;55(6):711-716.

22. Henderson CJ, Abonia JP, King EC, et al. Comparative dietary therapy effectiveness in remission of pediatric eosinophilic esophagitis. J Allergy Clin Immunol. 2012;129(6):1570-1578.

23. Almansa C, Krishna M, Buchner AM, et al. Seasonal distribution in newly diagnosed cases of eosinophilic esophagitis in adults. $\mathrm{Am} \mathrm{J}$ Gastroenterol. 2009;104(4):828-833.

24. Wang FY, Gupta SK, Fitzgerald JF. Is there a seasonal variation in the incidence or intensity of allergic eosinophilic esophagitis in newly diagnosed children? J Clin Gastroenterol. 2007;41(5):451-453.

25. Peterson KA, Byrne KR, Vinson LA, et al. Elemental diet induces histologic response in adult eosinophilic esophagitis. Am J Gastroenterol. 2013;108(5):759-766.

26. Feuling MB, Noel RJ. Medical and nutrition management of eosinophilic esophagitis in children. Nutr Clin Pract. 2010;25(2): $166-174$.

27. Spergel JM, Andrews T, Brown-Whitehorn TF, Beausoleil JL, Liacouras CA. Treatment of eosinophilic esophagitis with specific food elimination diet directed by a combination of skin prick and patch tests. Ann Allergy Asthma Immunol. 2005;95(4):336-343.

28. Spergel JM, Brown-Whitehorn TF, Cianferoni A, et al. Identification of causative foods in children with eosinophilic esophagitis treated with an elimination diet. J Allergy Clin Immunol. 2012;130(2):461-467. e5.

29. Spergel JM, Beausoleil JL, Mascarenhas M, Liacouras CA. The use of skin prick tests and patch tests to identify causative foods in eosinophilic esophagitis. J Allergy Clin Immunol. 2002;109(2):363-368.

30. Vicario M, Blanchard C, Stringer KF, et al. Local B cells and $\operatorname{IgE}$ production in the oesophageal mucosa in eosinophilic oesophagitis. Gut. 2010;59(1):12-20.

31. Yen EH, Hornick JL, Dehlink E, et al. Comparative analysis of FcepsilonRI expression patterns in patients with eosinophilic and reflux esophagitis. J Pediatr Gastroenterol Nutr. 2010;51(5):584-592.

32. Mishra A, Schlotman J, Wang M, Rothenberg ME. Critical role for adaptive $\mathrm{T}$ cell immunity in experimental eosinophilic esophagitis in mice. J Leukoc Biol. 2007;81(4):916-924.

33. Noti M, Wojno ED, Kim BS, et al. Thymic stromal lymphopoietinelicited basophil responses promote eosinophilic esophagitis. Nat Med. 2013;19(8):1005-1013.

34. Rocha R, Vitor AB, Trindade E, et al. Omalizumab in the treatment of eosinophilic esophagitis and food allergy. Eur J Pediatr. 2011;170(11): 1471-1474.

35. Dehlink E, Fiebiger E. The role of the high-affinity IgE receptor, FcepsilonRI, in eosinophilic gastrointestinal diseases. Immunol Allergy Clin North Am. 2009;29(1):159-170, xii.

36. Aceves SS. Food allergy testing in eosinophilic esophagitis: what the gastroenterologist needs to know. Clin Gastroenterol Hepatol. September 11, 2013. [Epub ahead of print; In press 2014.]

37. Al-Hussaini A, Al-Idressi E, Al-Zahrani M. The role of allergy evaluation in children with eosinophilic esophagitis. $J$ Gastroenterol. 2013;48(11):1205-1212.

38. Rizo Pascual JM, De La Hoz Caballer B, Redondo Verge C, et al. Allergy assessment in children with eosinophilic esophagitis. J Investig Allergol Clin Immunol. 2011;21(1):59-65.

39. Molina-Infante J, Martin-Noguerol E, Alvarado-Arenas M, Porcel-Carreno SL, Jimenez-Timon S, Hernandez-Arbeiza FJ. Selective elimination diet based on skin testing has suboptimal efficacy for adult eosinophilic esophagitis. J Allergy Clin Immunol. 2012;130(5):1200-1202. 
40. Gonzalez-Cervera J, Angueira T, Rodriguez-Dominguez B, Arias A, Yague-Compadre JL, Lucendo AJ. Successful food elimination therapy in adult eosinophilic esophagitis: not all patients are the same. J Clin Gastroenterol. 2012;46(10):855-858.

41. Simon D, Straumann A, Wenk A, Spichtin H, Simon HU, Braathen LR. Eosinophilic esophagitis in adults - no clinical relevance of wheat and rye sensitizations. Allergy. 2006;61(12):1480-1483.

42. Spergel JM, Brown-Whitehorn T, Beausoleil JL, Shuker M, Liacouras CA. Predictive values for skin prick test and atopy patch test for eosinophilic esophagitis. J Allergy Clin Immunol. 2007;119(2):509-511.

43. Jesenak M, Banovcin P, Rennerova Z, et al. Reproducibility of food atopy patch tests over time in the general child population. Int $J$ Dermatol. 2009;48(9):941-946.

44. Heine RG, Verstege A, Mehl A, Staden U, Rolinck-Werninghaus C, Niggemann B. Proposal for a standardized interpretation of the atopy patch test in children with atopic dermatitis and suspected food allergy. Pediatr Allergy Immunol. 2006;17(3):213-217.
45. Kagalwalla AF, Shah A, Li BU, et al. Identification of specific foods responsible for inflammation in children with eosinophilic esophagitis successfully treated with empiric elimination diet. $J$ Pediatr Gastroenterol Nutr. 2011;53(2):145-149.

46. Sampson HA. Update on food allergy. J Allergy Clin Immunol. 2004;113(5):805-819.

47. Gonsalves N, Yang GY, Doerfler B, Ritz S, Ditto AM, Hirano I. Elimination diet effectively treats eosinophilic esophagitis in adults; food reintroduction identifies causative factors. Gastroenterology. 2012;142(7):1451-1459. e1.

48. Lucendo AJ, Arias A, Gonzalez-Cervera J, et al. Empiric 6-food elimination diet induced and maintained prolonged remission in patients with adult eosinophilic esophagitis: a prospective study on the food cause of the disease. J Allergy Clin Immunol. 2013;131(3):797-804.

49. Teitelbaum JE, Fox VL, Twarog FJ, et al. Eosinophilic esophagitis in children: immunopathological analysis and response to fluticasone propionate. Gastroenterology. 2002;122(5):1216-1225.

\section{Publish your work in this journal}

The Journal of Asthma and Allergy is an international, peer-reviewed open-access journal publishing original research, reports, editorials and commentaries on the following topics: Asthma; Pulmonary physiology; Asthma related clinical health; Clinical immunology and the immunological basis of disease; Pharmacological interventions and

\section{Dovepress}

new therapies. Issues of patient safety and quality of care will also be considered. The manuscript management system is completely online and includes a very quick and fair peer-review system, which is all easy to use. Visit http://www.dovepress.com/testimonials.php to read real quotes from published authors.

Submit your manuscript here: http://www.dovepress.com/journal-of-asthma-and-allergy-journal 